\title{
Stereological characterization of crack path transitions in ceramic matrix composites
}

\author{
PARAG BHARGAVA* and B R PATTERSON ${ }^{\dagger}$ \\ Materials Science Centre, Indian Institute of Technology, Kharagpur 721 302, India \\ ${ }^{\dagger}$ University of Alabama at Birmingham, AL 35294, USA
}

\begin{abstract}
All ceramic composites involve a mismatch in physical properties the extent of which differs from one composite to another. Mismatch in thermal expansion $(\Delta \alpha)$ and elastic modulus $(\Delta \mathrm{E})$ is known to produce stresses that influence the path of a propagating crack. Thus, the relative effect of thermal and elastic mismatch on the crack path is expected to change with change in stress intensity. We propose that the crack path in ceramic composites should undergo a transition with the crack being strongly influenced by the thermal mismatch stresses at low stress intensity and elastic mismatch stresses at high stress intensities. Thus, a material in use under different applications each with its own loading conditions is expected to exhibit different crack propagation tendencies which may be reflected in the $v-K$ characteristics of the composite material. In the present work several model composites with different combinations of thermal and elastic mismatch have been considered. Cracks propagating at different sub-critical stress intensities (velocities) were generated by a novel indentation technique. Each indentation was performed at a constant displacement rate and a peak load. A range of displacement rates were used to produce cracks propagating at different velocities. The indentations were made using a Vickers indentor fitted in a universal mechanical testing machine. The crack paths in composites were quantified by stereological technique and the proposed theory was verified.
\end{abstract}

Keywords. Elastic mismatch; subcritical stress intensity; Vicker's indentor; $v-K$ characteristics.

\section{Introduction}

The extent to which the toughening mechanisms such as crack pinning, crack deflection, microcracking, and bridging in a composite material are active depends on the physical properties of the matrix and reinforcement, most importantly the thermal expansion coefficient $(\alpha)$ and elastic modulus $(E)$, and on the microstructural characteristics. Mismatch in $\alpha$ and $E$ between the matrix and reinforcement produces localized stresses, and their distribution is controlled by the microstructural state (i.e. reinforcement volume fraction, size, morphology, and orientation). Cracks are attracted towards reinforcements with values of $\alpha$ and $E$ lower than those of the matrix and avoid reinforcements with higher values (Binns 1962).

The thermal mismatch residual stresses developed upon cooling from the high processing temperature remain constant while the elastic mismatch stresses increase with the applied stresses. Since most ceramic composites have non-negligible thermal expansion and elastic modulus mismatch, both $\Delta \alpha$ and $\Delta E$ stresses will exist at any stress intensity and the crack path will be

\footnotetext{
*Author for correspondence
}

influenced by the net stresses from their superposition. It is proposed that the relative effect of elastic mismatch vs that of thermal mismatch on crack path will increase with increasing crack tip stress intensity (Bhargava and Patterson 1996).

The individual effects of mismatch in $\alpha$ and $E$ on the crack path are predictable and have been identified in several prior studies (Binns 1962; Khaund et al 1977; Huang and Lin 1993), but only recently have the combined effects of thermal and elastic mismatch on the crack path in ceramic composites have been quantified (Bhargava and Patterson 1997). In this recent study, quantification of crack path in $c-\mathrm{ZrO}_{2} / 10 \mathrm{v} \% \quad \mathrm{Al}_{2} \mathrm{O}_{3}$ showed a transition in the crack propagation with stress intensity indicating increasing elastic mismatch influence on the crack path with increasing stress intensity. In a study on the glass $/ 10 \mathrm{v} \% \mathrm{Fe}-\mathrm{Co}-\mathrm{Ni}$ alloy particulate composites, Jessen and Lewis (1989) also observed differences in crack path with applied stress intensity.

Quantification of the crack path in ceramic composites provides a systematic evaluation of the role played by the different variables involved in the design of these materials. In the present study, these predictions have been verified through a quantification of the crack path in ceramic composites representing different combinations of thermal and elastic mismatch. 


\section{Experimental}

\subsection{Sample preparation}

Several composites with different combinations of thermal and elastic mismatch between the matrix and the reinforcement were produced. The composite systems and their component properties are shown in table 1.

The glass $/ 10 \mathrm{v} \%$ alumina composites were hot pressed to full density at temperature about $25^{\circ} \mathrm{C}$ below the softening points of the respective glasses. The alumina $/ 5 \mathrm{v} \%$ silicon carbide composite was hot pressed at $1700^{\circ} \mathrm{C}$. The alumina/zirconia composites were pressed uniaxially followed by a cold isostatic compaction, and sintering in air at $1650^{\circ} \mathrm{C}$ for $2 \mathrm{~h}$. The glass samples were manually ground on SiC abrasive paper (240-600 grit) and then carefully hand polished on flocked twill cloth with $1 \mu \mathrm{m}$ alumina slurry for a short time, to avoid particle pullout. The alumina/zirconia samples were ground on 45 and $15 \mu \mathrm{m}$ diamond wheels and polished on a silk cloth with a diamond paste from 9 through $1 \mu \mathrm{m}$. The alumina/10 v\% c-zirconia samples were thermally etched prior to indentation to determine the effect of intergranular fracture on overall crack path tendency.

\subsection{Vickers indentation}

Ceramic materials are known to develop cracks, accompanied by the release of stored elastic energy, during loading/unloading of the indentor. As shown by Cook and Pharr (1990), indentation cracks may nucleate very early during loading for crystalline materials and only upon unloading in (non-densifying) glasses, but in both types of materials the majority of the indentation cracks are formed on unloading the indentor. The rate of withdrawal of the indentor determines the rate of release of the elastic energy that determines the crack growth rate
(Salomonson and Rowcliffe 1996). The indentation experiments on pure alumina by Salomonson and Rowcliffe (1996) revealed that the mean crack velocity increased with increase in the unloading rate of the indentor. In the current study the crack growth rates were varied through the use of controlled loading and unloading of the indentor at different rates.

Indentations on the alumina/ $10 \mathrm{v} \% \quad c$-zirconia and $c$-zirconia/10 v\% alumina composites were performed using a conventional microhardness testing machine (Buehler Micromet II) at increasing indentation loads. Since the loading and unloading indentation cycles were completed in a fixed time interval, the indentations made at higher loads involved higher loading/unloading rates (Bhargava and Patterson 1997).

Indentations on the remaining composite materials i.e. glass/alumina, alumina/silicon carbide and PSA (3 mole\% yttria)/alumina, were made at Oak Ridge National Laboratory (ORNL) under more controlled loading conditions. Recognizing that the indentation rate could be significant in determining the crack growth rates (Bhargava and Patterson 1997; Salomonson and Rowcliffe 1996), indentations at ORNL were performed at a different constant cross-head rate. Usually these indentations also were performed at two different peak loads. All the above indentations were performed in normal laboratory conditions i.e. $20-24^{\circ} \mathrm{C}$ and $50-60 \%$ relative humidity. Indentation at different rates for each of the material systems were performed within a maximum duration of 2-3 $\mathrm{h}$ and all the indentations on the different materials were completed in a single day. Thus the humidity conditions for different comparisons in this study are assumed to be stable.

Indentation cracks formed at different loading/unloading rates propagated at different velocities corresponding to different sub-critical stress intensities (Bhargava and Patterson 1997). Crack growth rates presented in table 2 were not directly measured and they have been included

Table 1. Thermal and elastic mismatch in the composites in this study.

\begin{tabular}{|c|c|c|}
\hline Composite & $\begin{array}{c}\text { Thermal mismatch } \\
\left(\alpha_{\text {matrix }}-\alpha_{\text {reinforcement }}\right) \Delta T\end{array}$ & $\begin{array}{l}\text { Elastic mismatch } \\
E_{\text {reinforcement }} / E_{\text {matrix }}\end{array}$ \\
\hline $\begin{array}{l}\text { Glass } 1 / 10 \vee \% \mathrm{Al}_{2} \mathrm{O}_{3} \\
\text { (Case 3, table 2) }\end{array}$ & $\left(\alpha_{\text {glass }}-\alpha_{\text {alumina }}\right) \Delta T=9.7 \times 10^{-4}$ & $E_{\text {alumina }} / E_{\text {glass }}=5-7$ \\
\hline $\begin{array}{l}\mathrm{Al}_{2} \mathrm{O}_{3} / 5 \mathrm{v} \% \mathrm{SiC} \\
(\text { Case } 4, \text { table } 2)\end{array}$ & $\left(\alpha_{\text {alumina }}-\alpha_{\mathrm{SiC}}\right) \Delta T=44 \times 10^{-4}$ & $E_{\mathrm{SiC}} / E_{\text {alumina }}=1 \cdot 1$ \\
\hline $\begin{array}{l}\text { Glass } 2 / 10 \vee \% \mathrm{Al}_{2} \mathrm{O}_{3} \\
\text { (Case } 6 \text {, table 2) }\end{array}$ & $\left(\alpha_{\text {glass }}-\alpha_{\text {alumina }}\right) \Delta T=39 \times 10^{-4}$ & $E_{\text {alumina }} / E_{\text {glass }}=5-7$ \\
\hline $\begin{array}{l}\mathrm{ZrO}_{2} / 10 \vee \% \mathrm{Al}_{2} \mathrm{O}_{3} \\
(\text { Case } 6, \text { table 2) }\end{array}$ & $\left(\alpha_{\text {zirconia }}-\alpha_{\text {alumina }}\right) \Delta T=36 \times 10^{-4}$ & $E_{\text {alumina }} / E_{\text {zirconia }}=2$ \\
\hline $\begin{array}{l}\mathrm{Al}_{2} \mathrm{O}_{3} / 10 \mathrm{v} \% \mathrm{c}-\mathrm{ZrO}_{2} \\
(\text { Case } 8, \text { table 2) }\end{array}$ & $\left(\alpha_{\text {alumina }}-\alpha_{\text {zirconia }}\right) \Delta T=-36 \times 10^{-4}$ & $E_{\text {zirconia }} / E_{\text {alumina }}=0 \cdot 5$ \\
\hline $\begin{array}{l}\text { Glass } 3 / 10 \mathrm{v} \% \mathrm{Al}_{2} \mathrm{O}_{3} \\
\text { (Case } 9, \text { table 2) }\end{array}$ & $\left(\alpha_{\text {glass }}-\alpha_{\text {alumina }}\right) \Delta T=-33 \times 10^{-4}$ & $E_{\text {alumina }} / E_{\text {zirconia }}=5-7$ \\
\hline
\end{tabular}


here to illustrate that the indentation rate has a significant influence on the mean crack growth rates (Salomonson and Rowcliff 1996).

\subsection{Stereological measurements and analysis}

The crack propagation depends much on the property mismatch and $K_{\mathrm{I}}$ on the interaction between the crack and reinforcement induced microstructure (table 3 ). The tendency of crack attraction or repulsion can be charac-

Table 2. Cross-head rate and peak load for Vicker's indentation and the associated mean crack growth rates.

\begin{tabular}{|c|c|c|c|}
\hline Composite & $\begin{array}{c}\text { Indentation } \\
\text { (cross-head) } \\
\text { rate }(\mu \mathrm{m} / \mathrm{s})\end{array}$ & $\begin{array}{c}\text { Indentation } \\
\text { peak load } \\
(\mathrm{N})\end{array}$ & $\begin{array}{c}\text { Approximate } \\
\text { crack growth } \\
\text { rate }(\mu \mathrm{m} / \mathrm{s}) \\
\text { (crack length/ } \\
\text { unloading time) }\end{array}$ \\
\hline \multirow{3}{*}{$\begin{array}{l}\text { Glass } 2 / 10 \mathrm{v} \% \\
\text { alumina } \\
\text { (Case } 6 \text {, table 2) }\end{array}$} & $0 \cdot 08$ & $\begin{array}{l}102 \\
208\end{array}$ & $\begin{array}{l}0.23 \\
0.76\end{array}$ \\
\hline & $0 \cdot 43$ & $\begin{array}{l}114 \\
252\end{array}$ & $\begin{array}{l}4 \cdot 50 \\
2 \cdot 10\end{array}$ \\
\hline & 100 & $\begin{array}{l}123 \\
254\end{array}$ & $\begin{array}{r}580 \\
2000\end{array}$ \\
\hline \multirow{2}{*}{$\begin{array}{l}\text { Glass } 1 / 10 \mathrm{v} \% \\
\text { alumina } \\
\text { (Case } 3 \text {, table 2) }\end{array}$} & $0 \cdot 43$ & $\begin{array}{l}110 \\
269\end{array}$ & $\begin{array}{l}2 \cdot 8 \\
4 \cdot 2\end{array}$ \\
\hline & 100 & $\begin{array}{l}114 \\
272\end{array}$ & $\begin{array}{l}680 \\
950\end{array}$ \\
\hline \multirow{2}{*}{$\begin{array}{l}\text { Glass } 3 / 10 \mathrm{v} \% \\
\text { alumina } \\
\text { (Case 9, table 2) }\end{array}$} & 0.43 & $\begin{array}{l}101 \\
250\end{array}$ & $\begin{array}{l}1 \cdot 1 \\
1 \cdot 9\end{array}$ \\
\hline & 100 & $\begin{array}{l}120 \\
287\end{array}$ & $\begin{array}{l}330 \\
400\end{array}$ \\
\hline
\end{tabular}

terized by the stereological 'degree of contact' parameter, $R$ (Aigeltinger and Exner 1977; Patterson and Liu 1990; Patterson et al 1990; Liu and Patterson 1993) defined as the ratio of the amount of crack surface or length of crack trace contacting the particulate reinforcement (i.e. particle debond or fracture) to the amount of surface that would contact the particles by random intersection.

The lengths of crack traces on a polished sample are directly proportional to the surface areas of the various types of cracks in the three-dimensional structure. The fraction of the total crack length expected to interact with particles on a random basis is equal to the particle volume fraction, i.e.

$$
R=\frac{\begin{array}{c}
\text { Fraction of crack length in contact } \\
\text { with the reinforcements }
\end{array}}{\text { Volume fraction of reinforcements }} .
$$

Thus, the computed value of $R$ would be unity for random crack-particle contact and greater or less than unity for preferred particle contact or avoidance, respectively. In particular, the above method is able to account for the tendency of cracks to be deflected towards the equator or the poles of particles. When cracks have a tendency to be deflected towards the poles, the average debond lengths decrease, resulting into a lower fraction of the crack length interacting with the particles and lower values of $R$.

All crack path quantifications were performed on SEM micrographs that were recorded at a fixed magnification and zero degree tilt. An image analysis system was used to digitize and measure the lengths of the different types of crack path. For most of the composites, backscattered micrographs were used to confirm the nature of the crack path in regions in which the cracks appeared too bright to resolve well in the secondary electron mode. For the

\begin{tabular}{|c|c|c|c|c|}
\hline \multirow[b]{2}{*}{ Case } & \multirow[b]{2}{*}{$\begin{array}{l}\text { Elastic } \\
\text { mismatch }\end{array}$} & \multicolumn{3}{|c|}{ Crack interactions with reinforcement } \\
\hline & & $\begin{array}{c}\text { Low } K_{\mathrm{I}}^{*} \\
\text { Dominant influence: } \Delta \alpha\end{array}$ & & $\begin{array}{c}\text { High } K_{\mathrm{I}}^{*} \\
\text { Dominant influence: } \Delta E\end{array}$ \\
\hline & & & $\alpha_{\mathrm{m}}=\alpha_{\mathrm{r}}$ & \\
\hline 1. & $E_{\mathrm{m}}=E_{\mathrm{r}}$ & Random & & Random \\
\hline 2. & $E_{\mathrm{m}}>E_{\mathrm{r}}$ & Random & & Attraction \\
\hline 3. & $E_{\mathrm{m}}<E_{\mathrm{r}}$ & Random & & Avoidance \\
\hline 4. & $E_{\mathrm{m}}=E_{\mathrm{r}}$ & Attraction & $\alpha_{\mathrm{m}}>\alpha_{\mathrm{r}}$ & Attraction \\
\hline 5. & $\begin{array}{l}L_{\mathrm{m}}-L_{\mathrm{r}} \\
E_{\mathrm{m}}>E_{\mathrm{r}}\end{array}$ & Attraction & & Increased attraction \\
\hline 6. & $E_{\mathrm{m}}<E_{\mathrm{r}}$ & Attraction & & Avoidance \\
\hline & & & $\alpha_{\mathrm{m}}<\alpha_{\mathrm{r}}$ & \\
\hline 7. & $E_{\mathrm{m}}=E_{\mathrm{r}}$ & Avoidance & & Avoidance \\
\hline 8. & $E_{\mathrm{m}}>E_{\mathrm{r}}$ & Avoidance & & Attraction \\
\hline 9. & $E_{\mathrm{m}}<E_{\mathrm{r}}$ & Avoidance & & Increased attraction \\
\hline
\end{tabular}

Table 3. Effect of property mismatch and $K_{\mathrm{I}}$ on crack-microstructure interactions.

*The magnitude of low and high $K_{\mathrm{I}}$ will be different for different materials. 
above reason, backscattered electron micrographs were used for all indentation cracks in all the glass/alumina composites.

In the alumina/zirconia composites, typically 20 cracks (five indents) were analysed to obtain the overall trends for indentation at the lowest load. For longer cracks at higher loads fewer cracks, typically 8-12 (2-3 indents), were quantified. Statistical analysis indicated that the crack lengths used for each of the system were sufficiently long to sample the composite microstructures.

Since the difference in the mean crack growth rates corresponding to the indentation rates used was significant the effect of any small variations in the local indentation crack velocity could be ignored by considering the average crack path tendency over the whole indentation crack. Thus, the data presented in this study represents the mean crack path tendencies. Almost all the data points included in this study had a coefficient of variation (CV) below 0.20.

\section{Results}

The results from the crack path quantification in five of the nine possible combinations of thermal and elastic mismatch in composites are presented below. In these studies Vickers indentations were preformed at different loading and unloading (cross-head) rates to generate cracks with different propagation velocities (Salomonson and Rowcliff 1996) corresponding to different subcritical stress intensities $\left(K_{\mathrm{I}}<K_{\mathrm{IC}}\right)$. The indentation cracks were digitized and characterized using several of the previously described techniques.

\subsection{Preferred crack path-Degree of crack-particle contact, $R$}

Figure 1 illustrates the effect of indentor loading/unloading rate (i.e. applied stress intensity) on the degree of crackparticle contact in several particulate composites with different thermal and elastic modulus mismatch between the matrix and reinforcement. These different experimental curves correspond to cases in table 3 .

For case 6 the matrix has a higher $\alpha$ and lower $E$ than the reinforcement, which should cause crack attraction to the particles at low $K_{\mathrm{I}}$ but crack avoidance at higher $K_{\mathrm{I}}$ i.e. a transition in path with applied $K_{\mathrm{I}}$. The curve for case 6 in figure 1, for a glass $/ 10 \mathrm{v} \%$ alumina composite shows exactly this predicted trend transitioning from almost 2 times greater than the random contact at a indentor cross-head rate of $0.08 \mu \mathrm{m} / \mathrm{s}$ to avoidance $(R<1)$ at a rate of $100 \mu \mathrm{m} / \mathrm{s}$ (higher indentation crack velocity and $K_{\mathrm{I}}$ ).

For the above glass/alumina composite, the indentation fracture toughness at the higher velocity, whether crack deflection occurred or not, was found to be nearly 2.4 times greater than for the slower crack growth rate, which had much greater crack-particle contact. In this composite, crack deflection around the particles imparts much greater toughening than crack-particle intersection, where the crack was locally accelerated toward the particles under the influence of the thermal residual stress. For composites with stronger particle-matrix interface, ductile particles or other shapes and orientations of reinforcement, the degrees of crack-particle contact might have correlated differently with fracture toughness than in the above example where crack deflection (avoidance) produced more toughening than particle intersection.

The curve in figure 1 for case 9 (see table 3 ) represents a glass $/ 10 \mathrm{v} \%$ alumina composite with the matrix having a lower $\alpha$ and $E$ than the alumina particles. Again this experimental plot shows the expected trend in crackparticle interaction of crack avoidance $(R=0.4$ times random) due to the $\Delta \alpha$ effect at low applied $K_{\mathrm{I}}$ and still greater avoidance $(R=0 \cdot 2)$ at higher $K_{\mathrm{I}}$ when both $\Delta \alpha$ and $\Delta E$ effects have the same tendency on the crack path. This trend is in contrast to that of case 6 above, showing a crack path transition resulting from the opposing crack steering tendencies due to $\Delta \alpha$ and $\Delta E$.

In figure 1 curve corresponding to case 3 (table 3 ) is for a glass $/ 10 \mathrm{v} \%$ alumina composite with very small thermal mismatch. Thus, the degree of contact was less than random at high loading rate and approached random $(R=1)$ with a decrease in the indentation loading rate. For this composite the average debond length per particle interaction was found to decrease from $5.3 \mu \mathrm{m}$ to $4.5 \mu \mathrm{m}$ with an increase in indentation cross-head rate from $0.4 \mu \mathrm{m} / \mathrm{s}$, indicating greater crack deflection towards the poles of the particles at higher indentation rates.

The curve in figure 1 for case 4 (see also table 3 ) shows the behaviour of an alumina/ $10 \mathrm{v} \%$ silicon carbide composite for which the thermal expansion mismatch should cause crack attraction to the particles and the closeness of the elastic moduli should have little further effect with increasing $K_{\mathrm{I}}$. Again, this experimental result

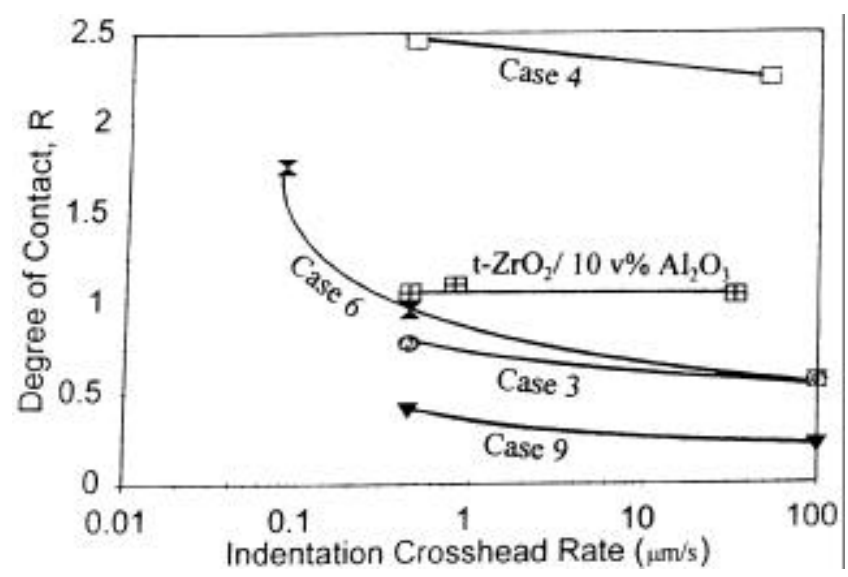

Figure 1. Crack-particle contact, $R$ vs loading/unloading indentation cross-head rate curves for ceramic composites. 
is similar to the predicted behaviour with 2.5 times random contact at the low loading rates and only a slight decrease in contact at higher rate, due to the slightly greater modulus of $\mathrm{SiC}$ relative to alumina.

The experimental curve in figure 1 for PSA/10 v\% $\mathrm{Al}_{2} \mathrm{O}_{3}$ shows a variation of case 6 , in which the transitioning behaviour shown above for the glass/10 v\% alumina composite is suppressed by other effects. Here, the indentation causes a transformation of the partially stabilized matrix, creating compressive stresses that constrain the crack to a planar path. The experimental plot shows a random crack path $(R=1)$ with no tendency for attraction or avoidance since deviations from a straight path were prevented.

Figure 2 shows the results obtained from the crack path quantification of $c$-zirconia/10 v\% alumina and alumina/10 v\% c-zirconia composites. As described earlier, the indentations on these materials were made using a regular Vickers microhardness indentation machine with the loading rate increasing with the peak indentation load. In this figure the loading rates have been normalized by the rate corresponding to the indentation made at the lowest load of $0.5 \mathrm{~N}$. The $c$-zirconia/ $10 \mathrm{v} \%$ alumina composite is a case 6 system in which thermal expansion mismatch caused crack attraction to the alumina particles and the elastic mismatch stress caused particle avoidance. Again, as predicted, the crack path underwent a transition with increase in crack velocity (indentation loading rate). It was found that the degree of crack-particle contact was 1.8 times random at the lowest indentation rate and that it decreased sharply and then stabilized at 1.3 times random at the higher indentation rates (figure 2). This behaviour indicates a decreased crack attraction to the particles due to the increasing influence of the elastic mismatch stress at the higher indentation rates. In contrast to the case 6 system in figure 1 (glass $/ 10 \mathrm{v} \%$ alumina) the measured degree of contact at high indentation rates does not fall below unity

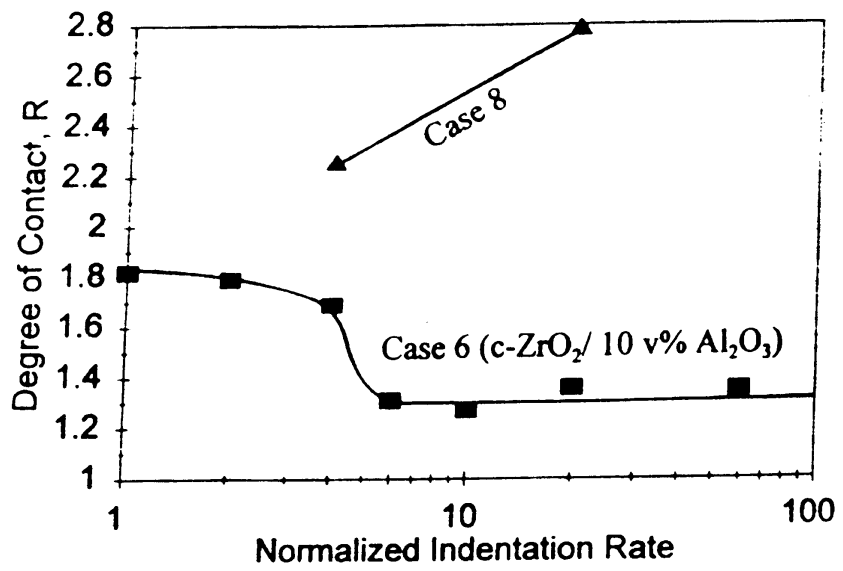

Figure 2. Degree of crack-particle contact, $R$ vs loading/ unloading indentation rate for alumina/10 $\mathrm{v} \% \quad c$-zirconia (case 8 ) and $c$-zirconia/10 v\% alumina (case 6) composites. since even if the crack was driven more towards the poles of the particles, the occurrence of the particle-matrix debond in this material allowed the degree of contact to remain slightly greater than random.

For a case 8 composite, the degree of contact should have been less than the random $(R<1)$ for low stress intensities, transitioning to a preferred contact $(R<1)$ at the higher stress intensities. Figure 2 shows the experimentally observed crack propagation tendencies for an alumina/10 v\% $c$-zirconia composite having the $\Delta \alpha$ and $\Delta E$ characteristics of a case 8 material. Although the degree of contact increased with the stress intensity as expected, the low stress intensity contact was markedly greater. The reason for this enhanced contact in this material was the preferential intergranular fracture in the alumina matrix, increasing the crack particle contact. In the above composite, $42 \%$ of the crack length through the matrix was along the alumina grain boundaries for the indentation rates used and the alumina grain boundaries had about 2 times more zirconia particles (Wickman 1996) on the grain boundaries than was expected from random contact. Thus, fracture along the grain boundaries in the above composite caused the degree of crackparticle contact to be higher than was expected from the effect of residual mismatch stresses. This effect of the intergranular fracture on increasing the degree of crackparticle contact was apparent from the fact that at the lower indentation rate (low crack velocity) nearly $70 \%$ of the intersected particles were contacted following a grain boundary fracture. With an increase in indentation rate, the percentage of particles intersected by the crack following grain boundary fracture decreased to nearly $50 \%$. Since the percentage of intergranular fracture remained the same at the higher indentation rate, more particles per unit crack length were intersected by cracks propagating through the alumina grains. Thus, the degree of contact increased independent of the intergranular fracture, as predicted for lower modulus particles at a higher crack velocity. This tendency was also seen in the increased $R$, as shown in figure 2 .

In the above figures 1 and 2, increasing values on the $x$-axis correspond to an increasing influence of the elastic mismatch effect (vs thermal mismatch) on the crack path. The testing rates (crack velocity or $K_{\mathrm{I}}$ ) at which the present authors have observed, the crack path transitions (i.e. from $\Delta \alpha$ to $\Delta E$ influence) have always been very low, as seen for the case 6 curve in figure 1 . It should be noted that conventional mechanical property evaluations involving fast fracture are typically performed at or beyond the high end of the $x$-axis in the above plot. The implication of this is that properties obtained under conventional fast fracture conditions most likely reflect predominant elastic mismatch control with little or no influence of thermal mismatch. In contrast, mechanical behaviour under the testing or service conditions involved slow crack growth which will primarily be 
influenced by the thermal mismatch stresses with less influence from the elastic mismatch.

\section{Conclusions}

(I) Quantification of crack path through the use of stereological methods has provided an improved understanding of the mechanisms of crack propagation in ceramic composites.

(II) The relative influence of the elastic mismatch stresses vs thermal mismatch on crack path in the ceramic composites increased with the crack tip stress intensity, as predicted by the proposed inferences.

(III) The quantitative crack path measurements and the approximate crack growth rates obtained from the total crack length per indentor unload time indicated change in crack velocity with indentation rate and indentation peak load.

\section{Acknowledgements}

The HTML User Program and assistance from Drs $\mathrm{S}$ Raghuraman and M K Ferber in performing the controlled indentation experiments are gratefully acknowledged. We also thank the Alabama NSF-EPSCoR program on Composite Interfaces for financial support, and the following companies for supplying samples of some of the powders used in this study-Ferro Corp. (glass), Sumitomo (alumina) and Performance Ceramics Co. (3YPSZ).

\section{References}

Aigeltinger E H and Exner H E 1977 Metall. Trans. A8 421

Bhargava P and Patterson B R 1996 Crack-microstructure interactions in ceramic matrix composites, $\mathrm{Ph} \mathrm{D}$ Dissertation, University of Alabama, Birmingham, USA

Bhargava P and Patterson B R 1997 J. Am. Ceram. Soc. 80 1863

Binns D B 1962 Science of ceramics (ed) G H Stewart (New York: Academic Press) 1 p. 315

Cook R F and Pharr G M 1990 J. Am. Ceram. Soc. 73787

Huang J L and Lin J C 1993 J. Mater. Sci. 281074

Jessen T L and Lewis D III 1989 J. Am. Ceram. Soc. 72 818

Khaund A K, Krstic V D and Nicholson P S 1977 J. Mater. Sci. 122269

Liu Y and Patterson B R 1993 Metall. Trans. A24 1497

Patterson B R and Liu Y 1990 J. Am. Ceram. Soc. 733703

Patterson B R, Liu Y and Griffin J A 1990 Metall. Trans. A21 2137

Salomonson J and Rowcliffe D J 1996 Philos. Mag. A74 1265

Wickman C 1996 Particle inhibited grain growth, MS Thesis, University of Alabama at Birmingham, USA 